\title{
A PRODUÇÃO CINEMATOGRÁFICA DE UM PONTO DE VISTA HISTÓRICO-ECONÔMICO
}

Guilherme Pinto Ravazi

\begin{abstract}
RESUMO
Pretendo neste artigo investigar os motivos pelos quais a produção cinematográfica parece gerar tão poucas obras relevantes em proporção ao volume de filmes produzidos mundialmente. $\mathrm{O}$ artigo se divide em duas partes. Na primeira, abordo a história da criação e as primeiras reflexões sobre o cinema. Na segunda, comparo as abordagens do cinema elaboradas por Benjamin e Adorno considerando as implicações econômicas na produção cinematográfica.
\end{abstract}

Palavras-chave: Cinema. Vanguardas. Walter Benjamin. Theodor Adorno. Indústria Cultural.

\section{THE FILM PRODUCTION ON AN HISTORIC-ECONOMIC PERSPECTIVE}

\section{ABSTRACT}

The aim of this paper is to investigate the reason why the film production seems to generate only a few relevant works when compared to the volume of films produced worldwide. The paper is divided into two parts. First, I discuss the history of creation and the first reflections about films. Second, I compare the Benjamin's and Adorno's approaches on film from the point of view of the economic implications of film production.

Keywords: Cinema. Vanguardas. Walter Benjamin. Theodor Adorno. Cultural Industry. 
$\mathrm{Na}$ introdução do livro Tudo sobre cinema, o crítico e historiador de cinema Philip Kemp faz uma curiosa afirmação sobre a produção da indústria cinematográfica:

Em qualquer época, provavelmente não mais do que $5 \%$ da produção mundial merece uma atenção mais do que passageira - e talvez esse número esteja superestimado. ${ }^{1}$

À primeira vista esse pensamento parece exagerado. No entanto, se analisarmos friamente, o número de filmes do passado que são lembrados e admirados até hoje é muito inferior em relação à produção geral da época em que foi lançado. Para usar um exemplo mais próximo: de todos os filmes lançados no período em que o cinema faz parte da minha própria vida cotidiana, de quantos conseguirei lembrar como artisticamente relevantes? Mas aqui surge outra questão: como avaliamos a relevância de um filme? $\mathrm{E}$ por que há tão poucos de boa qualidade em relação à produção geral? O objetivo deste ensaio é tentar responder a essas perguntas por meio de uma investigação que tem como ponto de partida o nascimento do cinema e os primeiros estudos filosóficos direcionados à sétima arte. Percorrendo a história de sua criação e os debates que causou no meio estético e social, talvez venhamos a compreender as causas dessa disparidade.

\section{AS ARTES DE VANGUARDA E O NASCIMENTO DO CINEMA}

A invenção do cinema ocorreu em um contexto histórico e estético bastante peculiar. O ano de 1895 é aceito pela maioria dos estudiosos como a data de "nascimento" do cinema, pois neste ano ocorreu a primeira exibição pública de um filme - a Saída dos operários da fábrica Lumière gravado pelos inventores da câmera cinematográfica, os irmãos Louis e Auguste Lumière. As primeiras películas consistiam apenas de cenas reais do cotidiano. Filmes com uma narrativa identificável começaram a ser produzidos logo em seguida já no início do século XX. Nesse período, o meio artístico passava por um fenômeno de ruptura com a tradição. Em todos os campos da arte (pintura, escultura, literatura, etc.), novas tendências surgiam as quais negavam os princípios estéticos anteriormente vigentes

\footnotetext{
1 KEMP, 2012, p. 11.
}

Guilherme Pinto Ravazi - Graduação Bacharelado em Filosofia da Universidade Federal de Santa Maria (UFSM). Brasileiro, residente em Santa Maria - RS, E-mail: gp.ravazi@ hotmail.com 
na história da arte. Nesse contexto, nasceu a chamada 'arte de vanguarda' que abrangia correntes artísticas tais como o Cubismo, o Dadaísmo, o Futurismo, o Surrealismo e o Expressionismo. Apesar dos artistas assumirem-se deliberadamente como membros de um determinado movimento vanguardista, nenhuma dessas correntes constituiu um estilo de época. Na verdade, o ideal da arte de vanguarda era justamente a negação de qualquer estilo. Até então, o meio artístico era regido por um conjunto predeterminado de procedimentos que só poderiam ser excedidos dentro dos limites estabelecidos pelo estilo dominante. A arte de vanguarda eliminou essa característica ao "erigir um princípio de disponibilidade sobre os meios artísticos de épocas passadas". ${ }^{2}$ Nesta fase do desenvolvimento da arte, o "choque do receptor" tornou-se o mais elevado princípio da intenção artística.

No ensaio A desumanização da arte, Ortega y Gasset afirma que a brusca ruptura com o passado mudou drasticamente o modo de se perceber a arte. Segundo ele, na obra de arte tradicional o prazer estético obtido ao se contemplar, por exemplo, a pintura de uma paisagem devia-se ao prazer que sentiríamos se estivéssemos no ambiente representado caso ele fosse real. O drama de um romance só poderia ser apreciado se nos importássemos com o destino humano dos personagens. Nesta arte jovem, porém, "o objeto artístico só é artístico na medida em que não é real". ${ }^{3}$ Com efeito, o cinema foi muito criticado em seus primeiros anos de existência por ser a simples reprodução do real. Junto à fotografia, suscitou um intenso debate entre estetas e artistas sobre o merecimento ou não do estatuto de arte. Gasset não considera o cinema em sua reflexão, pois está interessado na obra de arte não figurativa. Apesar disso, não se pode negar a estreita relação do cinema com a arte de vanguarda: passou a existir no mundo uma nova sensibilidade estética representada pelos novos movimentos artísticos que floresceram no século em questão. Até o século XIX a arte se desenvolveu organicamente com o curso da história, harmonizando o antigo e o novo. Com essa ruptura com o passado, tudo o que restou à arte foram atualidades artísticas desprovidas de qualquer ligação com a realidade. No entanto, no famoso ensaio A obra de arte na era de sua reprodutibilidade técnica, Walter Benjamin afirma que muitos dos efeitos requeridos pela nova sensibilidade estética só foram plenamente alcançados por meio do

\footnotetext{
BÜRGER, 2012, p. 46.

3 ORTEGA Y GASSET, 2008, p. 27.
}

Guilherme Pinto Ravazi - Graduação Bacharelado em Filosofia da Universidade Federal de Santa Maria (UFSM). Brasileiro, residente em Santa Maria - RS, E-mail: gp.ravazi@ hotmail.com 
cinema. "O dadaísmo tentava obter com os meios da pintura (ou literatura) os mesmos efeitos que o público busca hoje no filme". ${ }^{4} \mathrm{O}$ que antes o dadaísmo tentava atingir por meio de um choque moral, o cinema o faz com um choque físico. O elemento fílmico da distração funciona de um modo "tátil". A mudança de cenários e planos atinge o espectador com um impacto. Segundo Gasset, a arte jovem se tornou extremamente impopular, pois a maioria, a massa, não a entendia. A arte jovem, no entanto, era apreciada pelos próprios artistas: era preciso dispor dos conhecimentos de um artista para se poder compreender a arte jovem. O cinema, por outro lado, foi rapidamente abraçado pela massa e sua popularidade tornou-se incontestável até os dias de hoje.

Fazer um paralelo entre o cinema e a arte jovem, tal como descrita por Gasset, é interessante porque suas respectivas características, quando contempladas ao mesmo tempo, pareceriam descrever realidades muito distintas entre si. Porém, como vimos, o cinema apresentado por Benjamin se aproxima bastante da arte jovem. Tanto que grandes expoentes desta operaram também no cinema fundando o movimento avant-garde. Como, exemplo podemos citar o dadaísta Marcel Duchamp com o seu hipnótico Anémic Cinéma (1926), o cubista Hans Richter e seu geométrico Rhythmus 21 (1921), a surrealista Germaine Dulac e o provocativo La Coquille et Le Clergyman (1928) entre muitos outros.

Benjamin atribui a popularidade do cinema também a outro fenômeno artístico de sua época, originado pelo desenvolvimento das técnicas de reprodução: a preferência do valor de exposição, isto é, a possibilidade da arte ser apreciada em diversos lugares e por diversas pessoas, em detrimento do valor de culto ligado ao ritual. Este, ao contrário, determina que quanto mais "escondida" está a obra, mais valor ela possui. O desenvolvimento das técnicas de reprodução provocou uma acentuada atrofia na "aura" das obras de arte em geral. Benjamin define aura como "o aqui e agora da obra de arte - sua existência única no local em que se encontra" Este "aqui e agora" é o que concede a autenticidade da obra de arte. Porém, quando o valor da arte se submete à aura, sua fruição fica restrita a um pequeno grupo de indivíduos. A visão de uma estátua dedicada a um deus, por exemplo, é restrita aos praticantes da religião em questão e ao acesso ao templo onde ela se encontra. A

\footnotetext{
4 BENJAMIN, 2013, p. 87.

5 BENJAMIN, 2013, p. 53.
}

Guilherme Pinto Ravazi - Graduação Bacharelado em Filosofia da Universidade Federal de Santa Maria (UFSM). Brasileiro, residente em Santa Maria - RS, E-mail: gp.ravazi@ hotmail.com 
contemplação de certos quadros é restrita apenas ao colecionador abastado o suficiente para manter uma coleção de pinturas. A característica limitadora do "valor de culto" foi responsável por sua substituição pelo "valor do objeto como realidade exibível". As técnicas de reprodução possibilitaram a emancipação da arte de sua existência parasitária que lhe era imposta pelo seu valor ritualístico. As condições sociais que possibilitaram essa emancipação foram as seguintes: a exigência das massas de que as coisas se lhe tornassem espacialmente e humanamente mais próximas; acolhendo as reproduções, tenderam a depreciar o caráter das coisas que são dadas apenas uma vez. Anteriormente, a obra original sempre teve o privilégio em relação à sua reprodução. Porém, esse privilégio não se mantém com o desenvolvimento das técnicas de reprodução, pois, além de reproduzir a obra original com uma perfeição nunca antes vista, as reproduções levam as artes a lugares, nos quais talvez, elas jamais seriam vistas. Antes, as obras faziam parte do edifício no qual se encontravam. Era preciso se deslocar até a obra de arte. O local no qual se observa uma obra fornece um contexto, faz parte de seu significado. Assim, com a reprodutibilidade a quantidade de significados de uma mesma obra é proporcional à quantidade de reproduções feitas a partir dela. Tendo isto em vista, o critério de autenticidade deixa de ser tão valorizado na produção artística, pois o aqui e agora do original constituía a base deste critério. Em outras palavras, a autenticidade representa o caráter do objeto ser um mesmo idêntico ao longo do tempo e inserido em uma determinada cultura que comprova a sua unicidade. $O$ aspecto revolucionário das técnicas de reprodução se deve ao fato delas não somente reproduzirem obras já existentes como produzir obras originais para as quais o fato de serem reproduzíveis tecnicamente constitui o seu fundamento.

O cinema desempenhou um papel decisivo nesse processo, pois tornou-se a mais bem sucedida expressão artística fundamentada em sua própria reprodutibilidade. Porém, antes dele, a fotografia já havia despertado uma grande polêmica sobre se o estatuto de arte poderia lhe ser atribuído. Benjamin afirma que esta polêmica nasceu de um falso problema baseado em uma confusão. Na verdade, a polêmica era "a expressão de uma transformação histórica mundial, da qual nenhuma de ambas as partes estava consciente enquanto tal". ${ }^{6} \mathrm{O}$ abalo nas

${ }^{6}$ BENJAMIN, 2013, p.66.

Guilherme Pinto Ravazi - Graduação Bacharelado em Filosofia da Universidade Federal de Santa Maria (UFSM). Brasileiro, residente em Santa Maria - RS, E-mail: gp.ravazi@ hotmail.com 
bases ritualísticas da arte tornou impossível a manutenção de sua autonomia. Como consequência, a arte passaria a ter um caráter funcional. Os artistas e teóricos preocuparam-se em discutir se a fotografia era ou não arte, sem, no entanto, se perguntarem se sua própria invenção não mudaria o caráter geral da 'arte'. O mesmo aconteceu com o cinema, mas o impacto que este causou na arte foi imensamente maior.

\section{BENJAMIN E ADORNO: CINEMA COMO PRODUTO CULTURAL}

Em contraste com a abordagem otimista de Benjamin em relação ao cinema, seu colega da Escola de Frankfurt, Adorno, elabora uma crítica contundente ao cinema e à indústria cultural em geral no livro Indústria Cultural e Sociedade. Diz ele: "O cinema e o rádio não tem mais necessidade de serem empacotados como arte. $A$ verdade de que nada são além de negócios lhes serve de ideologia. Esta deverá legitimar o lixo que produzem de propósito". ${ }^{7}$ Enquanto Benjamin considerava o cinema como um instrumento de libertação das massas, Adorno o percebe como um recurso de dominação. Pois o cinema seria responsável por criar uma ideia do humano totalmente genérica e estandardizada. Este ideal, apesar de não interferir na liberdade do corpo aprisionaria o espírito. "O patrão não diz mais: ou pensas como eu ou morres. Mas diz: é livre para não pensares como eu, a tua vida, os teus bens, tudo será deixado, mas, a partir deste instante, és um intruso entre nós". 8

Apesar da diferença entre as posições de Adorno e Benjamin, ambos chamam a atenção para realidades que podem ser observadas ainda hoje. Por conseguinte, uma avaliação comparada dessas duas análises pode ajudar a responder a algumas de nossas inquietações acerca dos produtos da indústria cinematográfica.

Uma das teses mais importantes defendida por Benjamin refere-se à mudança da práxis da arte em decorrência do desenvolvimento das técnicas de reprodução. Até então, em virtude de seu caráter de culto, a arte se fundava numa práxis ritual. A partir da invenção da fotografia e do cinema, cujas obras se fundamentam no fato de sua reprodutibilidade, a arte passa a ter a política como

\footnotetext{
7 ADORNO, 2012, p.8.

8 ADORNO, 2012, p. 25.
}

Guilherme Pinto Ravazi - Graduação Bacharelado em Filosofia da Universidade Federal de Santa Maria (UFSM). Brasileiro, residente em Santa Maria - RS, E-mail: gp.ravazi@ hotmail.com 
práxis. A democratização da apreciação da arte - agora a arte não é mais restrita a um determinado grupo privilegiado - é uma evidência disso. No contexto do desenvolvimento técnico "o filme serve para exercitar o homem nas apercepções e reações que são exigidas para se lidar com uma aparelhagem cujo papel em sua vida aumenta quase que diariamente". ${ }^{9} \mathrm{O}$ filme é capaz de aumentar o entendimento sobre as coerções que regem a existência humana por meio de seu enorme leque de recursos técnicos e artísticos. O close-up e a câmera lenta ajudam a perceber elementos do nosso inconsciente visual com uma desenvoltura admirável. Cada movimento, toda flutuação de humor, quadro a quadro, pouca coisa escapa à câmera.

A abordagem de Adorno sobre o cinema está inserida em uma reflexão mais ampla que engloba todos os produtos da indústria cultural: rádio, revistas, semanários, soap operas, etc. Segundo o autor, a indústria cultural opera de modo que todos os seus produtos adquirem um ar de semelhança. Com a participação de milhões de consumidores a indústria cultural atende a necessidades iguais com produtos estandardizados por meio das técnicas de reprodução. Desse modo, "o ambiente em que a técnica adquire tanto poder sobre a sociedade encarna o próprio poder dos economicamente mais fortes sobre a mesma sociedade". ${ }^{10}$ As opiniões de Benjamin sobre o cinema podem ser otimistas, mas não são ingênuas. $O$ autor também estava atento a este problema. Benjamin assevera que a partir do momento em que o ator de cinema se coloca diante de uma câmera, sua imagem é transportada para uma massa de espectadores que por sua vez constituem um mercado. Os produtos que a indústria cinematográfica oferece não são apenas os filmes, mas também a própria vida privada das estrelas de cinema exploradas pelos jornais e revistas de fofoca: "Tudo isso para falsificar e corromper o interesse original e justificado das massas pelo filme - um interesse do autoconhecimento, e portanto, do conhecimento de classe". ${ }^{11}$ Enquanto o capital cinematográfico controlar a produção dos filmes não se pode exigir que o cinema faça mais do que uma crítica

9 BENJAMIN, 2013, p. 63.

${ }^{10}$ ADORNO, 2012, p. 9.

${ }^{11}$ BENJAMIN, 2013, p. 79.

Guilherme Pinto Ravazi - Graduação Bacharelado em Filosofia da Universidade Federal de Santa Maria (UFSM). Brasileiro, residente em Santa Maria - RS, E-mail: gp.ravazi@ hotmail.com 
das representações tradicionais da arte. ${ }^{12} \mathrm{~A}$ crítica social e revolucionária fica restrita a poucos casos particulares. No entanto, para Adorno, mesmo esses casos particulares servem apenas para consolidar ainda mais o sistema por meio do qual os filmes são produzidos: "Todas as violações do exercício da profissão cometidas por Orson Welles the são perdoadas porque - incorreções calculadas - só fazem confirmar e reforçar a validez do sistema". ${ }^{13}$

Segundo Adorno, os filmes são produzidos de acordo com um esquema que torna a produção homogênea. $O$ esquematismo faz com que todos os filmes apresentem sempre a mesma estória de maneiras variadas. Desde a primeira cena de um filme é possível saber quais personagens serão punidos e quais recompensados. $\mathrm{O}$ esquematismo gera uma diferenciação apenas ilusória de seus produtos:

Distinções enfáticas, como entre filmes de classe $A$ e $B$, ou entre histórias em revistas de diferentes preços, não são tão fundadas na realidade, quanto, antes, servem para classificar e organizar os consumidores a fim de padronizá-los. ${ }^{14}$

No vocabulário dos estúdios de cinema a distinção entre classe $A$ e $B$ se refere apenas ao valor monetário da produção. Os filmes mais caros são chamados de classe $A$ e os mais baratos de classe $B$. Esta distinção não exerce nenhuma influência no valor estético dos filmes, pois não são poucos os casos em que produções independentes de baixo orçamento tornam-se clássicos, ao mesmo tempo em que filmes com orçamentos exorbitantes são relegadas ao esquecimento. Supondo que o autor tenha usado a classificação $A$ e $B$ em termos de valor estético e que a classe $A$ se refira aos filmes conhecidos como filmes de arte, e a classe $B$ àqueles mais ordinários, produzidos para gerar grandes bilheterias como os blockbusters americanos, diríamos que os filmes da classe A são mais "valiosos" que os filmes da classe B. Se o que Adorno afirma é verdade, então devemos considerar o seguinte: geralmente os cinéfilos e pessoas que possuem maior intimidade com os filmes, apreciam estas duas classes de cinema. Porém, dentro da

\footnotetext{
${ }^{12}$ A significação social do filme, mesmo em seu aspecto mais positivo - e justamente nele - revela-se impensável sem esse seu lado destrutivo, catártico: a liquidação do valor de tradição e herança cultural (BENJAMIN, 2013, p. 35).

${ }_{14}^{13}$ ADORNO, 2012, p. 19.

${ }^{14}$ ADORNO, 2012, p. 11.
}

Guilherme Pinto Ravazi - Graduação Bacharelado em Filosofia da Universidade Federal de Santa Maria (UFSM). Brasileiro, residente em Santa Maria - RS, E-mail: gp.ravazi@ hotmail.com 
própria produção de blockbusters encontramos filmes memoráveis, e neste sentido as "obras de mestres" não são privilégio da classe "mais elevada". Em termos econômicos, a demanda por filmes que geram diversão, como é o caso dos blockbusters, é muito maior do que a demanda por filmes de arte. Desse modo, arrisco-me a dizer que o grande volume das produções cinematográficas é gerado exatamente do modo como Adorno descreve. Uma gigantesca produção de filmes praticamente iguais. Logo, o fato de haver poucos filmes realmente memoráveis deve-se, principalmente, a este fator econômico. Aquela pequena parcela de filmes que merecem uma atenção mais do que passageira estaria mais perto do ideal cinematográfico defendido por Benjamin.

O cinema nasce em um período de crise artística. Afirma-se como arte em um período em que a própria Arte, com letra maiúscula, estava em questão. Evolui de simples reprodução da realidade para arte revolucionária em um espaço de poucos anos. Populariza-se constituindo um mercado sempre em expansão. As inesgotáveis possibilidades das técnicas cinematográficas fazem do cinema o meio de expressão artístico mais versátil que já existiu. Capaz de produzir obras de arte inesquecíveis e filmes descartáveis vistos apenas como uma fonte rápida e barata de entretenimento e diversão. Porém, mesmo os filmes "baratos" carregam uma mensagem, que em muitos casos é opressora, como mostrado por Benjamin e Adorno. Por esse motivo, é preciso uma conscientização ${ }^{15}$ por parte do espectador de cinema sobre os produtos que consome. Não com o objetivo de evitá-los, mas sim para refinar o "gosto" pelo cinema a fim de desfrutar, com ainda mais prazer, aqueles filmes que de fato merecem ser lembrados e não se deixar levar pela frivolidade do, infelizmente comum, princípio: "um filme só é bom se ele me diverte".

\footnotetext{
${ }^{15}$ Neste artigo não elaborei as formas dessa conscientização, mas como esta é uma pesquisa em andamento esta questão poderá ser abordada em um trabalho futuro.
} 


\section{REFERÊNCIAS}

ADORNO, T. Indústria cultural e sociedade. Trad. Julia Elisabeth Levy. São Paulo: Paz e Terra, 2002.

BENJAMIN, W. A obra de arte na era de sua reprodutibilidade técnica. Trad. Gabriel Valladão Silva. Porto Alegre, RS: L\&PM, 2013.

BÜRGER, P. Teoria da vanguarda. Trad. José Pedro Antunes. São Paulo: Cosac Naify, 2012.

KEMP, P. Tudo sobre cinema. Trad. Fabiano Morais. Rio de Janeiro: Sextante, 2011.

ORTEGA Y GASSET, J. A desumanização da arte. Trad. Ricardo Araújo. São Paulo: Cortez, 2008. 